\title{
Relationship Between Follicular Fluid and Serum Levels of Vitamin C and Oocyte Morphology and Embryo Quality in Patients Undergoing In Vitro Fertilization
}

\author{
Seyedeh Hajar Sharami ${ }^{1}$, Mohammad Hadi Bahadori ${ }^{2}$, Fereshteh Fakor ${ }^{*}$, Fariba Mirblouk ${ }^{1}$, Sodabeh \\ Kazemi $^{1}$, Davood Pourmarzi ${ }^{2}$, Safoora Saffari ${ }^{3}$, Seyedeh Fatemeh Dalil Heirati ${ }^{1}$
}

\begin{abstract}
Objectives: This study aimed to determine the relationship between follicular fluid (FF) and serum level of vitamin C and oocytes morphology and embryo quality in patients undergoing in vitro fertilization (IVF).

Materials and Methods: This is a cross-sectional study which was conducted on 50 women undergoing IVF in Al-Zahra hospital in Rasht, Iran during 2014. Vitamin C level in FF and serum were measured using high-performance liquid chromatography (HPLC). Retrieval oocyte morphology and obtained embryo quality were evaluated using inverted optical microscope.

Results: In our study 434 oocytes and 199 embryos were assessed. Frequencies of metaphase II (MII) oocytes were significantly higher at $1-1.5 \mathrm{mg} / \mathrm{dL}$ level of vitamin $\mathrm{C}$ in $\mathrm{FF}(86.4 \%)$ and $0.5-1 \mathrm{mg} / \mathrm{dL}$ serum level of vitamin $\mathrm{C}(83.2 \%)$. Odds of having MII oocytes at the $1-1.5 \mathrm{mg} / \mathrm{dL}$ level of vitamin $\mathrm{C}$ in $\mathrm{FF}$ (odds ratio $[\mathrm{OR}]=15.02,95 \% \mathrm{CI}=2.77-81.54$ ) was 15 times greater than the level of $1.5-2.3 \mathrm{mg} / \mathrm{dL}$. The most frequency of embryo with $\mathrm{Z} 1$ or Z2 quality were observed at $0.1-0.5 \mathrm{mg} / \mathrm{dL}$ level of vitamin $\mathrm{C}$ in $\mathrm{FF}$ $(69.3 \%)$ and $0.5-1 \mathrm{mg} / \mathrm{dL}$ level of vitamin C in serum (84.3\%). odds of having embryo with Z1 or Z2 quality, at the 0.1-0.5 mg/dL level of vitamin $\mathrm{C}$ in $\mathrm{FF}(\mathrm{OR}=3.08,95 \% \mathrm{CI}=1.21-7.83)$, was 3 times greater compared to the $1-2.3 \mathrm{mg} / \mathrm{dL}$ level.

Conclusion: At the certain level of vitamin $\mathrm{C}$ in FF, clinicians may have oocytes with higher maturity and embryos with better quality.

Keywords: Embryo quality, Follicular fluid, IVF, Oocyte morphology, Vitamin C.
\end{abstract}

\section{Introduction}

In vitro fertilization (IVF) is one of the most common assisted reproductive technologies (ARTs). There are many factors that can affect IVF success $(1,2)$. Sperm and oocyte quality before fertilization and embryo quality before the transfer to the uterus are important factors for successful IVF treatment (1-3). Follicular fluid (FF) is an important environment for the development of oocytes. Composition of FF is of great importance for oocyte maturity and embryo quality $(4,5)$. Oxidative stress and reactive oxygen species (ROS) in the in vitro and body can reduce the success rate of IVF $(6,7)$. Vitamins which are known as antioxidants can reduce the excessive production of free radicals. They play important roles in spermatogenesis and oocyte development. It has been shown that the women with unexplained infertility had a lower total antioxidant status in their peritoneal fluid (8). The role of ascorbic acid in the neutralization of free radical species has been studied previously (9-11). Vitamin C the essential factor for follicle growth, ovulation, and corpus luteum development (12-14). Ascorbic acid can affect steroids, catecholamins, and neuroendocrine peptides synthesis and secretion $(15,16)$.
Previous animal studies mentioned inconsistent results. Some of them showed that ascorbic acid could inhibit follicular apoptosis and protect ovarian cells from oxidative damage (17-19) and some others mentioned negative and neutral effects of ascorbic acid on oocyte maturation and embryo quality $(7,11,20,21)$.

They reported that different levels of vitamin $C$ could have different effects on oocytes maturity and embryo quality $(11,18,19,22)$. According to the lack of human investigations, we aimed to determine the relationship between $\mathrm{FF}$ and serum vitamin $\mathrm{C}$ level with morphology of oocyte, and embryo quality in women undergoing IVF treatment.

\section{Materials and Methods}

This is a cross-sectional study which was conducted on 50 women undergoing IVF in Al-Zahra hospital in Rasht, Iran during 2014. Inclusion criterion was age between 20 and 45 years and women who actively smoked were excluded. Male and female age, female body mass index (BMI), duration of infertility, causes of infertility, and history of taking supplements containing vitamin $\mathrm{C}$ in the past two months were collected. 


\section{Ovulation Induction}

Similar ovulation induction protocol (gonadotropin-releasing hormone agonist or antagonist) was performed in all patients. The growth of the follicles was assessed every other day using transvaginal sonography, and if necessary, serum level of estradiol was measured as well. All patients received 10000 units of human chorionic gonadotropin (HCG), 36 hours before the oocyte retrieval.

Extraction of Follicles and Follicular Fluid Transvaginal oocyte retrieval was performed on days 10 to 14 of the menstrual cycle based on the follicles' size. Oocytes were collected 32 to 36 hours after the HCG injection. During puncture, procedure for removing the oocyte from the ovary, the follicles of at least $18 \mathrm{~mm}$ in diameter together with FF were aspirated by catheter. The oocytes were washed in G-MOPS ${ }^{\text {TM }}$ PLUS (Vitrolife, Sweden), and then they were held for 2 to 4 hours in incubator at temperature of $37^{\circ} \mathrm{C}$ and $\mathrm{CO}_{2}$ (as much as $6 \%$ ). Naked oocytes were kept in dishes containing the G-1 $1^{\text {TM }}$ PLUS (Vitrolife, Sweden) for IVF inside the incubator.

Assessing Oocyte Morphology, Fertilization and Embryo Quality

Oocytes assessments were done using an inverted microscope. Oocytes were categorized in three groups of metaphase II (MII), metaphase I (MI), germinal vesicle (GV), and degenerated. Fertilization assessment was done 15 to 20 hours after adding sperm. Male and female pronucleus formation was a mean for verification of fertilization. For embryo transfer, only 2-pronuclei $(2 \mathrm{PN})$ were used. The zygotes were scored using the Z-score scoring system. In this system, Z1 zygotes had equal numbers of arranged nucleoli in contrast to the adjacent pronuclei. Z2 zygotes had equal numbers of nucleoli with the similar size arranged in a nucleus on the side section but scattered in the other nucleus. Z3 zygotes had equal sizes and numbers of nucleoli in two nuclei, with one nucleus having aligned nucleoli at the pronuclear junction and the other having scattered nucleoli in itself. Zygotes with unequal numbers and/or sizes of nucleoli were also considered as Z3. Z4 zygotes that are unarranged pronuclei with slightly different sizes had not been located at the center of the zygote $(23,24)$.

\section{Measurement of Vitamin C}

Before oocyte retrieval, $5 \mathrm{~mL}$ blood sample was collected from each participant and $1 \mathrm{~mL}$ FF was taken. FFs were maintained by falcon tubes at $20^{\circ} \mathrm{C}$ after the suction and transferred to the laboratory. In order to avoid exposure to the light, the tubes were shielded in aluminum foil. Level of vitamin $\mathrm{C}$ was measured using High-performance liquid chromatography (HPLC) (IBL, Germany). All measurements were done in a predetermined laboratory.

\section{Statistical Analysis}

The obtained oocytes were divided to two groups of MII oocytes (mature oocytes) and other types (GV + MI + degeneration). The resulting embryos in the first day were divided to two groups (Z1 or Z2 and Z3 or Z4 quality groups). To investigate the effect of infertility on oocyte morphology and embryo quality, infertile women (female and combined infertility) were compared with healthy women (male infertility, unexplained, and donator) and infertile men (male infertility or combination infertility) were compared with healthy men (causes of female infertility and unexplained).

For data analysis, SPSS version 21.0 (SPSS Inc., Chicago, IL, USA) was used. Continuous data and categorized data were shown as mean \pm standard deviation (SD) and number (percentage), respectively. Chi-square test and Fisher exact test were used to compare the frequency between the groups. For comparing the mean between the two groups, the independent $t$ test was used. Pearson correlation coefficient test was used to assess the correlation between the level of vitamin $C$ with the number of oocytes and embryos and the levels of vitamin C in FF and serum. To evaluate the effect of studied variables on the oocyte maturity and embryo quality, logistic regression (Forward: LR) was used. A $P$ value less than 0.05 was considered statistically significant.

\section{Results}

Feature of Obtained Oocytes

A total of 434 oocytes were obtained. The mean number of oocytes was $8.66 \pm 5.23$ (range: 1 to 24 ). Most of the oocytes (349 cases, $80.4 \%$ ) were MII, 49 cases $(11.3 \%)$ were MI, 23 cases $(5.3 \%)$ were GV, and 13 cases (3\%) were degenerated.

Comparing Studied Variables Between the 2 Groups of Oocytes Morphology

There was significant difference among different age groups $(P=0.006)$ and infertility $(P=0.0001)$ in terms of frequency of MII oocytes (Table 1$)$.

The Level of Vitamin C in Follicular Fluid and its Relationship With Oocyte Morphology

There was no significant correlation between the number of oocytes and level of vitamin $\mathrm{C}$ in $\mathrm{FF}(\mathrm{r}=-0.054$, $P=0.710)$.

Mean level of vitamin $\mathrm{C}$ in FF between two groups of MII oocytes $(0.64 \pm 0.38 \mathrm{mg} / \mathrm{dL})$ and other oocytes $(0.74 \pm 0.45 \mathrm{mg} / \mathrm{dL})$ was statistically significant $(P=0.025)$. The minimum level of vitamin $C$ in our study samples was $0.1 \mathrm{mg} / \mathrm{dL}$, which was considered as the lower limit of first class. The highest observed level of vitamin C was $2.3 \mathrm{mg} /$ $\mathrm{dL}$ and considered as the upper limit of the last class. The highest frequency of MII oocytes (90.2\%) was observed in the $1-1.5 \mathrm{mg} / \mathrm{dL}$ level of vitamin $\mathrm{C}$. The lowest frequency of MII oocyte (60\%) was observed in the $1.5-2.3 \mathrm{mg} / \mathrm{dL}$ level of vitamin C (Table 2).

Vitamin C Serum Level and its Relationship With Oocyte Morphology

There was no significant correlation between the number of oocytes and vitamin $\mathrm{C}$ serum level $(\mathrm{r}=-0.027, P=0.850)$. 
Table 1. Comparing Frequency of MII Oocytes and Other Oocytes at Different Groups of Studied Variables

\begin{tabular}{|c|c|c|c|c|}
\hline Variables & & $\begin{array}{l}\text { MII } \\
\text { No. (\%) }\end{array}$ & $\begin{array}{l}\text { MI, GV, Degenerated } \\
\text { No. (\%) }\end{array}$ & $P$ Value \\
\hline \multirow{3}{*}{ Women age } & $23-29$ & $46(26.4)$ & $128(73.6)$ & \multirow{3}{*}{0.006} \\
\hline & $30-34$ & $25(17.7)$ & $116(82.3)$ & \\
\hline & $35-44$ & $14(11.8)$ & $105(88.2)$ & \\
\hline \multirow{3}{*}{ Women BMI } & $18-24.9$ & $103(82.4)$ & $22(17.6)$ & \multirow{3}{*}{0.771} \\
\hline & $25-29.9$ & $157(80.1)$ & 39 (19.9) & \\
\hline & $\leq 30$ & $89(78.8)$ & $24(21.2)$ & \\
\hline \multirow{2}{*}{ Women infertility duration (y) } & $>5$ & $108(85.7)$ & $18(14.3)$ & \multirow{2}{*}{0.084} \\
\hline & $\leq 5$ & $241(78.2)$ & $67(21.8)$ & \\
\hline \multirow{2}{*}{ Female factor infertility } & Yes & $152(90.5)$ & $16(9.5)$ & \multirow{2}{*}{0.0001} \\
\hline & No & $197(74.1)$ & $69(25.9)$ & \\
\hline \multirow{2}{*}{ Use of supplement containing vitamin C in women } & Yes & $77(85.6)$ & $13(14.4 \%)$ & \multirow{2}{*}{0.182} \\
\hline & No & $272(79.1)$ & $72(20.9 \%)$ & \\
\hline
\end{tabular}

Table 2. Comparing the Frequency Distribution of MII Oocytes and Other Oocytes Between Different Levels of Vitamin C in FF and Serum

\begin{tabular}{lllll}
\hline Vitamin C Level & & $\begin{array}{l}\text { MII } \\
\text { No. (\%) }\end{array}$ & $\begin{array}{l}\text { MI, GV, } \\
\text { Degenerated } \\
\text { No. (\%) }\end{array}$ & P \\
\hline \multirow{2}{*}{ Follicular fluid } & $0.1-0.5$ & $184(86.4)$ & $29(13.6)$ & 0.0001 \\
& $1-1.5$ & $122(71.8)$ & $48(28.2)$ & 0.0001 \\
& $1.5-2.3$ & $6(60)$ & $4(40)$ & 0.0001 \\
Women serum & $0.1-05$ & $220(79.7)$ & $56(20.3)$ & 0.0001 \\
\hline & $0.5-1$ & $124(83.2)$ & $25(16.8)$ & 0.113 \\
& $1-1.7$ & $5(55.6)$ & $4(44.4)$ & 0.113 \\
\hline
\end{tabular}

There was no significant difference between groups of MII oocytes $(0.47 \pm 0.29 \mathrm{mg} / \mathrm{dL})$ and other oocytes $(0.52 \pm 0.35$ $\mathrm{mg} / \mathrm{dL})$ regarding mean vitamin $\mathrm{C}$ serum level $(P=0.187)$.

The minimum level of vitamin $C$ was $0.1 \mathrm{mg} / \mathrm{dL}$, which was considered as the lower limit of first class. The highest level of observed vitamin $\mathrm{C}$ was $1.7 \mathrm{mg} / \mathrm{dL}$, which was considered as the upper limit of the last class. The highest percentage of MII oocyte (83.2\%) was observed in 0.5-1 $\mathrm{mg} / \mathrm{dL}$ level. The lowest frequency of MII oocyte was observed in the level of vitamin C 1-1.7 mg/dL. Frequency distribution of oocytes maturity among different groups of serum vitamin $\mathrm{C}$ level was not significant $(P=0.113)$ (Table 2).

\section{Feature of Developed Embryos}

From 45 cases, 199 embryos were obtained and from 5 cases, no embryo was obtained. The mean number of embryos was $3.98 \pm 2.98$ (range: 1 to 13 ). Most of them (102 cases, $51.3 \%$ ) had Z2 quality. Ten cases (5\%) had Z1 quality, 75 cases (37.7\%) had Z3 quality, and 12 cases (6\%) had Z4 quality.

Comparing Studied Variables Between the Two Groups of Embryo Quality

Frequency of embryo quality was significantly higher in women with less than 5 years infertility duration $(P=0.020)$. Also, this frequency in infertile men was significantly higher than fertile men $(P=0.001)$. The differ- ences of frequency distribution of embryos quality among the different female age, male age, female BMI, female infertility, and taking supplement containing vitamin C were not statistically significant (Table 3 ).

Vitamin C Level in Follicular Fluid and its Relationship With Embryo Quality

There was no significant correlation between vitamin C level in FF with the number of $2 \mathrm{PN}$ embryos $(\mathrm{r}=-0.008$, $P=0.954)$. The difference of mean level of vitamin $C$ between $\mathrm{Z} 1$ or Z2 quality $(0.58 \pm 0.29 \mathrm{mg} / \mathrm{dL})$ and Z3 or Z4 quality $(0.78 \pm 0.43 \mathrm{mg} / \mathrm{dL})$ was statistically significant $(P=0.0001)$. At 1.5-2.3 level of vitamin C, no embryo with $\mathrm{Z} 1$ and $\mathrm{Z} 2$ was observed. The most frequency of embryo with $\mathrm{Z} 1$ and $\mathrm{Z} 2$ quality (69.3\%) was observed in the 0.1 $0.5 \mathrm{mg} / \mathrm{dL}$ level of vitamin C. There was significant difference among different levels of vitamin $\mathrm{C}$ in FF regarding frequency of embryo quality $(P=0.001)$.

Serum Vitamin C Level and its Relationship With Embryo Quality

The correlation between serum vitamin $C$ level and the number of $2 \mathrm{PN}$ embryos $(\mathrm{r}=0.042, P=0.773$ ) was not significant. Mean level of vitamin $C$ between groups of embryos with Z1 or Z2 quality $(0.45 \pm 0.26 \mathrm{mg} / \mathrm{dL})$ and $\mathrm{Z} 3$ or Z4 quality $(0.57 \pm 0.33 \mathrm{mg} / \mathrm{dL})$ was significant $(P=0.004)$. The most frequency of embryo with $\mathrm{Z} 1$ and $\mathrm{Z} 2$ quality (63.7\%) was observed in the $0.5-1 \mathrm{mg} / \mathrm{dL}$ level of vitamin C. Frequency distribution of embryo quality among different levels of vitamin $\mathrm{C}$ serum was statistically significant $(P=0.015$; Table 4$)$.

The Effect of Vitamin C on the Oocyte Morphology Regression analysis showed that the odds of having MII oocytes in women aged 23-29 years compared with 3544 years old women was significantly lower $(P=0.0001)$. But this reduction of chance for women aged 30-34 years compared with age group 35-44 years was not significant $(P=0.203)$. Also, the odds of having MII oocytes in fertile women was significantly lower than infertile women $(P=0.0001)$. The odds of having MII oocytes at the level of $1-1.5 \mathrm{mg} / \mathrm{dL}$ of vitamin $\mathrm{C}$ in FF compared to level of 
Table 3. Comparing the frequency of embryo with $Z 1$ or $Z 2$ quality and Z3 or Z4 quality between different groups of studied variables

\begin{tabular}{|c|c|c|c|c|}
\hline Variables & & $\begin{array}{c}\mathrm{Z1}, \mathrm{Z2} \\
\text { No. (\%) }\end{array}$ & $\begin{array}{c}\mathrm{Z3}, \mathrm{Z4} \\
\text { No. (\%) }\end{array}$ & $P$ Value \\
\hline \multirow{3}{*}{ Women age } & $23-29$ & $46(56.1)$ & $36(43.9)$ & \multirow{3}{*}{0.555} \\
\hline & $30-34$ & 39 (60.9) & $25(39.1)$ & \\
\hline & $35-44$ & $27(50.9)$ & $26(49.1)$ & \\
\hline \multirow{2}{*}{ Men age } & $\geq 35$ & $57(57)$ & $43(43)$ & \multirow{2}{*}{0.887} \\
\hline & $<35$ & $55(55.6)$ & $44(44.4)$ & \\
\hline \multirow{3}{*}{ Women BMI } & $18-24.9$ & $37(53.6)$ & $32(46.4)$ & \multirow{3}{*}{0.821} \\
\hline & $25-29.9$ & $51(58.6)$ & $36(41.4)$ & \\
\hline & $30 \leq$ & $24(55.8)$ & $19(44.2)$ & \\
\hline \multirow{2}{*}{$\begin{array}{l}\text { Women infertility } \\
\text { duration }\end{array}$} & $>5$ & $52(66.7)$ & $26(33.3)$ & \multirow{2}{*}{0.020} \\
\hline & $\leq 5$ & $60(49.6)$ & $61(50.4)$ & \\
\hline \multirow{2}{*}{ Female infertility } & Yes & $47(58.8)$ & $33(41.3)$ & \multirow{2}{*}{0.662} \\
\hline & No & 65 (54.6) & $54(45.4)$ & \\
\hline \multirow{2}{*}{ Male infertility } & Yes & $58(70.7)$ & $24(29.3)$ & \multirow{2}{*}{0.001} \\
\hline & No & $54(46.2)$ & $63(53.8)$ & \\
\hline \multirow{2}{*}{$\begin{array}{l}\text { Use of supplement } \\
\text { containing vitamin C } \\
\text { in women }\end{array}$} & No & $94(59.1)$ & 65 (40.9) & \multirow{2}{*}{0.113} \\
\hline & Yes & $18(45.0)$ & $22(55.0)$ & \\
\hline
\end{tabular}

Table 4. Comparing Embryo Frequency With Z1 or Z2 Quality and Z3 or Z4 Quality in Different Groups of Vitamin C Level in the Follicular Fluid and Serum

\begin{tabular}{lllll}
\hline Vitamin C Level & & $\begin{array}{l}\text { Z1, Z2 } \\
\text { No. (\%) }\end{array}$ & $\begin{array}{l}\text { Z3, Z4 } \\
\text { No. (\%) }\end{array}$ & P value \\
\hline \multirow{3}{*}{ Follicular fluid } & $0.1-0.5$ & $70(69.3)$ & $31(30.7)$ & 0.001 \\
& $0.5-1$ & $31(43.1)$ & $41(56.9)$ & 0.001 \\
& $1-2.3$ & $11(42.3)$ & $15(57.7)$ & 0.001 \\
\hline \multirow{2}{*}{ Female serum } & $0.1-0.5$ & $65(63.7)$ & $37(36.3)$ & 0.015 \\
& $0.5-1$ & $45(51.7)$ & $42(48.3)$ & 0.015 \\
& $1-1.7$ & $2(20.0)$ & $8(80)$ & 0.015 \\
\hline
\end{tabular}

$1.5-2.3 \mathrm{mg} / \mathrm{dL}$ was significantly higher $(\mathrm{OR}=15.02,95 \%$ CI $=2.77-81.54)($ Table 5).

The Net Effect of Vitamin C on Embryo Quality

The odds of having an embryo with Z1 or Z2 quality in subjects with infertility duration less than 5 years was significantly higher than subjects with infertility duration higher than 5 years $(P=0.006)$. Odds of having an embryo with $\mathrm{Z} 1$ or $\mathrm{Z} 2$ quality in infertile male was significantly higher than fertile male $(P=0.0001)$. Odds of having embryo with Z1 or Z2 quality at the $0.1-0.5 \mathrm{mg} / \mathrm{dL}$ FF level of vitamin $\mathrm{C}(\mathrm{OR}=3.08,95 \% \mathrm{CI}=1.21-7.83)$ compared with the $1-2.3 \mathrm{mg} / \mathrm{dL}$ level was significantly higher (Table 5).

The correlation Between Vitamin C level in the Follicular Fluid and Serum

Significant direct correlation was found between level of vitamin $\mathrm{C}$ in the $\mathrm{FF}$ and serum $(\mathrm{r}=0.404, P=0.004)$.

\section{Discussion}

Based on our study, the highest frequency of MII oocyte was observed at $1-1.5 \mathrm{mg} / \mathrm{dL}$ level of vitamin $\mathrm{C}$ in FF. The odds of having MII oocyte in this level in FF was 15 times greater than $1.5-2.3 \mathrm{mg} / \mathrm{dL}$ level. But effect of different levels of vitamin $\mathrm{C}$ serum on oocyte maturity was not sig- nificant. The highest frequency of embryos with Z1 or Z2 quality was observed at $0.1-0.5 \mathrm{mg} / \mathrm{dL}$ level of vitamin $\mathrm{C}$ in FF. The odds of having embryos with $\mathrm{Z} 1$ or $\mathrm{Z} 2$ quality in this level in FF was 3 times greater than $1-2.3 \mathrm{mg} / \mathrm{dL}$ level. But effect of different levels of vitamin C serum on oocyte maturity was not significant.

Ascorbic acid could play significant role on steroidogenesis in the ovary. High concentrations of ascorbic acid reduced biosynthesis of steroid through prevention of hydroxylation systems (11). It was reported that high level of ascorbic acid might act as a pro-oxidant and had adverse effects on oocyte maturation $(10,25)$.

Tao et al showed that among 0, 50, 250 and $750 \mathrm{M} / \mathrm{ml}$ concentrations of ascorbic acid, only $250 \mathrm{M} / \mathrm{mL}$ level had positive effect on porcine denuded oocytes development from MI to MII and prevented cumulus cell DNA fragmentation (26). Michel et al demonstrated that none of 0 , 25,50 and $100 \mu \mathrm{g} / \mathrm{mL}$ of vitamin C supplementation in in vitro maturation (IVM) and in vitro culture (IVC) media affected nuclear maturation of oocytes. But supplementation of $50 \mu \mathrm{g} / \mathrm{mL}$ led to significantly increased intracellular glutathione levels and reduced ROS and improved cleavage rates, blastocyst rates and total cell numbers per blastocyst. Also supplementation with $50 \mu \mathrm{g} / \mathrm{mL}$ vitamin C decreased the apoptosis index as compared with the groups supplemented with $100 \mu \mathrm{g} / \mathrm{mL}$ (19). Barzegari Firouzabadi's study which investigated the effects of ascorbic acid on the IVM of mouse's follicles and enclosed oocytes mentioned that ascorbic acid could increase survival rate but did not affect diameter, GV breakdown, and oocyte maturation rates (22). In the study of Nadri et al, cumulusoocyte complexes (COCs) were incubated for 24 hours in the different concentrations of ascorbic acid. It was shown that increase in MII formation was statistically significant at the 80 and $250 \mathrm{M} / \mathrm{mL}$ ascorbic acid concentrations. But the reduction in MII formation was significant at the 750 $\mathrm{M} / \mathrm{mL}$ concentration of ascorbic acid compared with the $250 \mathrm{M} / \mathrm{mL}$ and the COCs of the $80 \mathrm{M} / \mathrm{mL}$ groups. Also the COCs achieved significantly higher maturation rate at the $250 \mathrm{M} / \mathrm{mL}$ concentration of ascorbic acid compared with the other groups. Their findings suggested that oocytes exposed to a high concentration of ascorbic acid might not mature adequately in vitro (11).

In the study of Wang et al which was conducted on the effect of antioxidant supplementation (vitamin $\mathrm{C}$ and vitamin E) on mouse embryo development, it was shown that co-incubating the embryos with vitamin $\mathrm{C}(50 \mu \mathrm{M})$ and the 12-phorbol 13-myristate acetate-activated supernatant significantly increased the blastocyst development (27). In the study of Miclea et al, sheep oocytes were cultured for 24 hours at $37^{\circ} \mathrm{C}$ in $5.4 \% \mathrm{CO}_{2}$ atmosphere in M199 containing $20 \mu \mathrm{M}$ a-tocopherol $+750 \mu \mathrm{M}$ ascorbic acid or $5 \mu \mathrm{M} \alpha$-tocopherol $+250 \mu \mathrm{M}$ ascorbic acid. They showed that the mixture of $20 \mu \mathrm{M} \alpha$ - tocopherol and 750 $\mu \mathrm{M}$ ascorbic had a beneficial effect on cytoplasmic maturation and a slightly detrimental one on nuclear maturation (28). In the study conducted by Kere et al on porcine oocytes, results showed that cytoplasmic maturation and 
Table 5. Regression Analysis of the Factors Affecting Oocyte Morphology and Embryo Quality

\begin{tabular}{|c|c|c|c|}
\hline Variables & OR & $95 \% \mathrm{Cl}$ & $\boldsymbol{P}$ \\
\hline \multicolumn{4}{|c|}{ Oocyte Morphology } \\
\hline \multicolumn{4}{|c|}{ Women age } \\
\hline $35-44$ & Reference & & \\
\hline $30-34$ & 0.62 & $0.29-1.30$ & 0.203 \\
\hline $23-29$ & 0.27 & $0.13-0.54$ & 0.0001 \\
\hline \multicolumn{4}{|c|}{ Female infertility } \\
\hline Yes & Reference & & \\
\hline No & 0.24 & $0.13-0.45$ & 0.0001 \\
\hline \multicolumn{4}{|c|}{ Follicular fluid vitamin C levels } \\
\hline $1.5-2.3$ & Reference & & \\
\hline $1-1.5$ & 15.02 & $2.77-81.54$ & 0.002 \\
\hline $0.5-1$ & 1.92 & $0.50-7.34$ & 0.340 \\
\hline $0.1-0.5$ & 3.57 & $0.91-13.92$ & 0.067 \\
\hline \multicolumn{4}{|c|}{ Embryo Quality } \\
\hline \multicolumn{4}{|c|}{ Infertility duration } \\
\hline$\leq 5$ & Reference & & \\
\hline$>5$ & 2.60 & $1.32-5.11$ & 0.006 \\
\hline \multicolumn{4}{|c|}{ Male infertility } \\
\hline Yes & Reference & & \\
\hline No & 0.21 & $0.10-0.44$ & 0.0001 \\
\hline \multicolumn{4}{|c|}{ Follicular fluid vitamin C levels } \\
\hline $1-2.3$ & Reference & & \\
\hline $0.5-1$ & 0.73 & $0.28-1.93$ & 0.523 \\
\hline $0.1-0.5$ & 3.08 & $1.21-7.83$ & 0.019 \\
\hline
\end{tabular}

subsequent development of oocytes could be improved by adding a low concentration of vitamin C during IVM but high concentrations of vitamin $\mathrm{C}$ could have some negative effects on oocytes development (29). In the study of Kazemi et al, results showed that vitamin $\mathrm{C}$ intake could increase the total antioxidant capacity level in FF and improving the oocyte competence (30). In other study by Griesinger et al, effect of receiving ascorbic acid $(1,5$, or $10 \mathrm{~g} / \mathrm{d}$ ) for 14 days after follicle aspiration for IVF-ET procedure on clinical pregnancy rate and implantation rate was not significant (21).

Fertility - the ability to produce offspring - is considered as a prerequisite for the development and perpetuation of species. Several factors might positively or negatively affect one's reproductive capabilities, such as regular exercises and maintaining a healthy bodyweight, versus aging, obesity, and stress. FF is a liquid composed primarily of hormones, enzymes, anticoagulants, electrolytes, ROS and antioxidants, which fills the follicular antrum and acts as an important mediator in the communication between cells in the antral follicle while bathing and carrying nutrients to the oocyte. The study of Basuino et al in 2016 is similar to our study because it approved effect antioxidant of FF. The oocytes and embryos are key elements for success of natural fertilization in every stage of the conception process, from the communication between gametes to the development of fully viable embryos, and a vital component in the occurrence of spontaneous pregnancies (31).

Paramio and Izquierdo in 2016 mentioned different results with our study in type of sample but was similar to the success of in vitro embryo production programs. Different criteria were used to select the best oocytes for fertilization, such as follicle size, oocyte diameter and morphological appearance. New research lines aimed at improve oocyte competence. 1) arresting nuclear maturation in vitro allowing optimal capacitation of cytoplasm, 2) growing oocytes inside the follicle, and 3) identification of biomarkers of oocyte competence in granulosa and cumulus cells and metabolites in the FF (32).

The study of Basini et al in 2016 was different with our study in type of sample but was similar to in rreactive oxygen and anti-oxidant defenses in FFs (33).

\section{Conclusion}

Based on our study, only at the certain level of vitamin $\mathrm{C}$ in FF oocyte, higher maturity and embryo with higher quality could be achieved. Lower and higher vitamin $C$ levels in FF had no effect on oocyte maturity and embryo quality. Also vitamin $\mathrm{C}$ serum level had no effect on oocyte maturity and embryo quality. Further studies to investigate effect of certain levels of vitamin $\mathrm{C}$ in $\mathrm{FF}$ on IVF success rate can be recommended.

\section{Ethical Issues}

The ethical approval was obtained from ethics committee of Guilan University of Medical Sciences (No. 1930162906). Written informed consent was obtained from all patients and their spouses.

\section{Conflict of Interests}

The authors declare that they have no conflicts of interest.

\section{Financial Support}

This study was financially supported by the Vicechancellorships Research of Guilan University of Medical Sciences.

\section{Acknowledgments}

The authors acknowledge with grateful appreciation the support provided by the Vice-chancellor of Research of Guilan University of Medical Sciences.

\section{References}

1. Elder K, Dale B. In-vitro fertilization. Cambridge University Press; 2010.

2. Huang JYJ, Rosenwaks Z. In vitro fertilisation treatment and factors affecting success. Best Pract Res Clin Obstet Gynaecol. 2012;26(6):777-788. doi:10.1016/j. bpobgyn.2012. 08.017.

3. Kruger TF, Menkveld R, Stander F, et al. Sperm morphologic features as a prognostic factor in in vitro fertilization. Fertil Steril. 1986;46(6):1118-1123.

4. Aflatoonian A, Mashayekhy M, Mohamadian F, Mansoori Moghaddam F. The correlation between follicular fluid anti-mullerian hormone levels and fertilization and embryo quality in ART cycles. Iran J Reprod Med. 2010;8(4):157160.

5. Revelli A, Delle Piane L, Casano S, Molinari E, Massobrio M, Rinaudo P. Follicular fluid content and oocyte quality: 
from single biochemical markers to metabolomics. Reprod Biol Endocrinol. 2009;7(40):4330-4337. doi: 10.1186/14777827-7-40.

6. Gardner DK. Dissection of culture media for embryos: the most important and less important components and characteristics. Reprod Fertil Dev. 2007;20(1):9-18. doi: 10.1071/RD07160

7. Tatemoto H, Sakurai N, Muto N. Protection of porcine oocytes against apoptotic cell death caused by oxidative stress during in vitro maturation: role of cumulus cells. Biol Reprod. 2000;63(3):805-810.

8. Polak G, Kozioł-Montewka M, Gogacz M, Błaszkowska I, Kotarski J. Total antioxidant status of peritoneal fluid in infertile women. Eur J Obstet Gynecol Reprod Biol. 2001;94(2):261-263. doi:10.1016/S0301-2115(00)00352-3.

9. Arrigoni O, De Tullio MC. Ascorbic acid: much more than just an antioxidant. Biochim Biophys Acta. 2002;1569(1):19.

10. Asard H, May J, Smirnoff N. Vitamin C: its functions and biochemistry in animals and plants. Garland Science; 2003.

11. Nadri B, Zeinoaldini S, Kohram H. Ascorbic acid effects on in vitro maturation of mouse oocyte with or without cumulus cell. Afr J Biotechnol 2009;8(20):5627-5631.

12. Himeno N, Kawamura N, Okamura H, Mori T, Fukumoto M, Midorikawa O. Collagen synthetic activity in rabbit ovary during ovulation and its blockage by indomethacin. Nihon Sanka Fujinka Gakkai Zasshi. 1984;36(10):1930-4.

13. Luck M, Zhao Y. Structural remodelling of reproductive tissues. J Endocrinol. 1995;146(2):191-5.

14. Luck M, Zhao Y. Identification and measurement of collagen in the bovine corpus luteum and its relationship with ascorbic acid and tissue development. J Reprod Fertil. 1993;99(2):647-52.

15. Eipper BA, Mains RE. The role of ascorbate in the biosynthesis of neuroendocrine peptides. Am J Clin Nutr. 1991;54(6):1153-1156.

16. Goralczyk R, Moser U, Matter U, Weiser H. Regulation of steroid hormone metabolism requires L-ascorbic acid. Ann N Y Acad Sci. 1992;669(1):349-351. doi:10.1111/j.1749-6632.1992.tb17120.x

17. Tilly JL, Tilly K. Inhibitors of oxidative stress mimic the ability of follicle-stimulating hormone to suppress apoptosis in cultured rat ovarian follicles. Endocrinology. 1995;136(1):242-252.

18. Kolodecik TR, Aten RF, Behrman HR. Ascorbic aciddependent cytoprotection of ovarian cells by leukocyte and nonleukocyte peroxidases. Biochem Pharmacol. 1998;55(9):1497-1503.

19. Michel K, Siriboon C, Neng-Wen L, Nguyen NT, JyhCherng J. Ascorbic acid improves the developmental competence of porcine oocytes after parthenogenetic activation and somatic cell nuclear transplantation. J Reprod Dev. 2013;59(1):78. doi:10.1262/jrd.2012-114.

20. Córdova B, Morató R, Izquierdo D, Paramio T, Mogas T. Effect of the addition of insulin-transferrin-selenium and/ or L-ascorbic acid to the in vitro maturation of prepubertal bovine oocytes on cytoplasmic maturation and embryo development. Theriogenology. 2010;74(8):1341-1348. doi:10.1016/j.theriogenology.2010.06.003.

21. Griesinger G, Franke K, Kinast C, et al. Ascorbic acid supplement during luteal phase in IVF. J Assist Reprod Genet. 2002;19(4):164-168.

22. Barzegari Firouzabadi F. Effects of ascorbic acid and FSH on the maturation of mice's oocytes and follicles. The Journal of Shahid Sadoughi University of Medical Sciences. 2011;19(5):586-97.

23. Scott L, Alvero R, Leondires M, Miller B. The morphology of human pronuclear embryos is positively related to blastocyst development and implantation. Hum Reprod. 2000;15(11):2394-2403.

24. Lan KC, Huang FJ, Lin YC, et al. The predictive value of using a combined Z-score and day 3 embryo morphology score in the assessment of embryo survival on day 5 . Hum Reprod. 2003;18(6):1299-306.

25. Rehman A, Collis CS, Yang M, et al. The effects of iron and vitamin $\mathrm{C}$ co-supplementation on oxidative damage to DNA in healthy volunteers. Biochem Biophys Res Commun. 1998;246(1):293-298.

26. Tao Y, Zhou B, Xia G, Wang F, Wu Z, Fu M. Exposure to L-ascorbic acid or alpha-tocopherol facilitates the development of porcine denuded oocytes from metaphase I to metaphase II and prevents cumulus cells from fragmentation. Reprod Domest Anim. 2004;39(1):52-57.

27. Wang X, Falcone T, Attaran M, Goldberg JM, Agarwal A, Sharma RK. Vitamin C and vitamin E supplementation reduce oxidative stress-induced embryo toxicity and improve the blastocyst development rate. Fertil Steril. 2002;78(6):1272-1277.

28. Miclea I, Pacală N, Hettig A, Zăhan M, Miclea V. Alphatocopherol and ascorbic acid combinations influence the maturation of sheep oocytes. Scientific Papers Animal Science and Biotechnologies. 2012;45(1):310-313.

29. Kere M, Siriboon C, Lo NW, Nguyen NT, Ju JC. Ascorbic acid improves the developmental competence of porcine oocytes after parthenogenetic activation and somatic cell nuclear transplantation. J Reprod Dev. 2012;59(1):78-84.

30. Kazemi A, Ramezanzadeh F, Nasr-Esfahani MH. The relations between dietary antioxidant vitamins intake and oxidative stress in follicular fluid and ART outcomes. Iran J Reprod Med. 2015;13(9):533.

31. Basuino L, Silveira CF Jr. Human follicular fluid and effects on reproduction. Jornal Brasileiro de Reprodução Assistida. 2016;20(1):38-40. doi:10.5935/1518-0557.20160009.

32. Paramio MT, Izquierdo D. Recent advances in in vitro embryo production in small ruminants. Int J Anim Reprod. 2016;86(1):152-159. doi:10.1016/j. theriogenology.2016.04.027.

33. Basini G, Simona B, Santini SE, Grasselli F. Reactive oxygen species and anti-oxidant defences in swine follicular fluids. Aust J Biol Sci. 2008;20(2):269-274.

Copyright ( 2017 The Author(s); This is an open-access article distributed under the terms of the Creative Commons Attribution License (http://creativecommons.org/licenses/by/4.0), which permits unrestricted use, distribution, and reproduction in any medium, provided the original work is properly cited. 